\title{
Input-output analyses of the pollution content of intra- and inter-national trade flows
}

Cathy Xin Cui

Soo Jung Ha

Geoffrey Hewings

Karen Turner

Stirling Economics Discussion Paper 2011-08

May 2011

Online at

http://www.management.stir.ac.uk/research/economics/workingpapers 


\title{
Input-output analyses of the pollution content of intra- and inter-national trade flows
}

by

\author{
Cui, Cathy Xin ${ }^{a}$, Ha, Soo Jung ${ }^{b}$, Hewings, Geoffrey ${ }^{c}$, and Turner, Karen ${ }^{d^{*}}$
}

a. Fraser of Allander Institute, Department of Economics, University of Strathclyde, Scotland

b. Korean Research Institute for Human Settlements, South Korea

c. Regional Economics Applications Laboratory, University of Illinois, US

d. Division of Economics, Stirling Management School, University of Stirling, Scotland

* Corresponding author: Division of Economics, Stirling Management School, University of Stirling, Cottrell Building, Stirling, FK9 4LA, Scotland, UK; Phone: +44 (0)1786 467474; karen.turner@stir.ac.uk

\section{Acknowledgements}

The research reported in this paper has been carried out with the support of the ESRC Climate Change Leadership Fellow project "Investigating the pollution content of trade flows and the importance of environmental trade balances" (ESRC ref. RES-066-27-0029), based at the Universities of Stirling and Strathclyde in the UK. It also draws on earlier research funded by the EPSRC through the SuperGen Marine Energy Research Consortium (Grant reference: EP/EO40136/1).We acknowledge the invaluable assistance of the Input-Output team at the Office of the Chief Economic Adviser, Scottish Government, and colleagues at the Stockholm Environment Institute (York, UK) in constructing the UK interregional input-output database used in this paper, and of Norihiko Yamano at the OECD in constructing the international trade and pollution data also used in the UK application. We also acknowledge the input of Angela Druckman, University of Surry, Max Munday, Cardiff Business School, and Peter McGregor and Kim Swales, both University of Strathclyde, for their insights and inputs on earlier research on the Fellowship project which provided a foundation for the work reported here. Finally, we are grateful to Janine De Fence and Stuart McIntyre for research assistance in the database construction. 


\section{Interregional input-output analyses of the pollution content of intra- and inter-national}

\section{trade flows}

\section{Abstract}

This paper considers the application of input-output accounting methods to consider the pollution implications of different production and consumption activities, with specific focus on pollution embodied in intra-and inter-national trade flows. We consider the illustrative case studies of interregional trade flows between two regions of the UK and between five Mid-West regions/states within the US. We focus on different types of air pollutant of current policy concern in each case and demonstrate how use of the environmental input-output framework allows us to analyse the nature and significance of interregional pollution spillovers. Our results raise questions in terms of the extent to which authorities at regional level can control local emissions where they are limited in the way some emissions can be controlled, particularly with respect to changes in demand elsewhere within the national economy. This implies a need for policy co-ordination between national and regional level authorities to meet emissions reductions targets. Moreover, the existence of pollution trade balances between regions also raises issues in terms of net losses/gains in terms of pollutants as a result of interregional trade. In conducting analyses for different types of air pollutant (here $\mathrm{CO} 2$ as a global warming gas, GHG, in the UK case and ammonia, NH3, as a pollutant of more local concern in the US case) we also consider how pollution embodied in international trade flows may be accounted for and attributed.

Keywords: Interregional input-output models; pollution trade balance; pollution attribution; air pollution

JEL codes: C67, D57, Q56, R15 


\section{Introduction}

In recognition of the problem of climate change an international agreement was reached in 1997 in Kyoto on reducing greenhouse gas emissions, particularly $\mathrm{CO} 2$. However, more than a decade later a number of issues hindering the reduction of emissions have yet to be resolved. Major challenges still remain in securing the cooperation of all nations and effective (and efficient) collective action within and between nations. It would seem that one crucial issue impacting on unilateral attempts to fulfil national emissions reductions targets under the Kyoto Protocol is the impact of international trade on any one country's domestic emissions generation. The problem is that the generation of emissions in producing goods and services to meet export demand is charged to the producing nation's emissions account. Munksgaard and Pedersen (2001) highlight this issue, distinguishing between a 'production accounting principle' (PAP) and a 'consumption accounting principle' (CAP). The former focuses on emissions produced within the geographical boundaries of the national economy. This is what is accounted for, and what individual national governments are responsible for reducing, under the Kyoto Protocol. In contrast, the latter focuses on emissions produced globally to meet consumption demand within the national economy. This is what increasingly popular measures such as carbon footprints attempt to measure, and what many people regard as more appropriate, given that human consumption decisions are commonly considered to lie at the heart of the climate change problem. In a closed economy, with no trade in goods and services, emissions accounts constructed under the production and consumption accounting principles would, by definition, be equal. However, where there is trade and pollution is embodied in that trade through emissions generated in one region or nation to meet consumption demand in another, these need not be equal.

In recognition of this point, an extensive discussion on the allocation of greenhouse gas emissions is conducted in the literature (e.g. Wyckoff and Roop, 1994; Kondo et al., 1998; Munskgaard and Pedersen, 2001; Ferng, 2003; Bastianoni et al., 2004; Sánchez-Chóliz and Duarte, 2004; Mongelli et al., 2006; Hoekstra and Janssen, 2006). In parallel to this discussion there has been a development of models and accounting techniques that are able to account for pollution embodied in trade, and this 
has mainly involved the use of input-output analyses. For example, Munksgaard and Pedersen (2001) identify a foreign 'trade balance' in pollution as the difference between total emissions estimated on the basis of the production and consumption accounting principles, or more simply, the difference between the pollution embodied in exports and the pollution embodied in imports. They use inputoutput techniques in order to distinguish between emissions under the consumption and production accounting principles and, in turn, to estimate a $\mathrm{CO} 2$ trade balance for Denmark. Particularly in the ecological footprint literature, where focus is on accounting for emissions under the consumption accounting principle, input-output analysis has become increasingly common in the academic literature as a technique to measure and allocate responsibility for emissions generation (see Wiedmann et al., 2007, and Wiedmann, 2009, for reviews). As explained by Turner et al. (2007) this would seem a natural development, given that the focus of consumption-based measures such as the carbon footprint is to capture the total (direct plus indirect) resource use embodied in final consumption in an economy. Input-output analysis is based around a set of sectorally disaggregated economic accounts, where inputs to each industrial sector, and the subsequent uses of the output of those sectors, are separately identified. Therefore, by the use of straightforward mathematical routines, the interdependence of different activities can be quantified, and all direct, indirect and, where appropriate, induced, resource use embodied within consumption can be tracked (Leontief, 1970, Miller and Blair, 2009).

However, there are several issues that are not fully addressed in the existing input-output pollution accounting literature. One is that appropriate data are not commonly available for full consumption accounting (which, in a globalised economy would essentially require a world interregional inputoutput accounting framework) and commonly have to be estimated. However, a second, and perhaps more fundamental, issue is that the extremes of the full PAP and CAP measures identified to date in the literature may not be appropriate for all pollutants or of practical policy interest. Linked to the latter point, another gap in the literature is that most applications to date have focussed on national economies and international trade. However, with increasing decentralisation of responsibility for setting and/or achieving environmental and other sustainability objectives, it is appropriate to extend 
the accounting focus to sub-national regional economies and the pollution content of inter-regional as well as international trade flows.

This paper attempts to address this latter set of issues, by considering the application of environmental input-output accounting techniques for different regional case studies and different types of air pollutant. In the second section we introduce the analytical environmental input output framework and consider alternative treatments of the pollution embodied in trade flows. In the third section we apply input-output accounting techniques to the case study of $\mathrm{CO} 2$ emissions generated in and/or attributable to the UK regions (focussing on the two-region case of Scotland and the rest of the UK). Following this we turn our attention a different geographical case with quite different policy concerns, focussing on the Midwest states of the US and ammonia (NH3) generation as an example of a nonGHG pollutant generated in a key trading sector of the regional economies therein (agriculture). The final section offers some conclusions and directions for future research.

\section{The analytical environmental input-output framework}

\subsection{The basic interregional environmental input-output framework applied to pollution generation}

We apply the interregional framework derived in Turner et al., (2007) to demonstrate an analytical IO method for enumerating the pollution content of trade flows. We begin with the standard, single region, Leontief inverse input-output equation (Leontief, 1970; Miller and Blair, 2009):

(1) $\mathbf{x}=(\mathbf{I}-\mathbf{A})^{-1} \mathbf{y}$

where $\mathbf{x}$ is a $N \times 1$ vector of gross outputs with elements $x_{i}$, where $i=1, \ldots, N$, for each economic sector, $i$, and $\mathbf{y}$ is an $N \times 1$ vector of final demands with corresponding elements $y_{i} . \quad \mathbf{A}$ is the 
technical coefficients matrix with elements $a_{i j}$, where $j=1, \ldots, M$ and $M=N$. The A-matrix is derived from the input-output transactions matrix, where $x_{i j}$ is the intermediate purchase of commodity output in sector $i$ as an input to production of output in sector $j, X_{j}$. Thus, each element of the A-matrix is formally defined as:

(2) $a_{i j}=x_{i j} / X_{j}$

Thus, the A matrix describes the intermediate demand for the output of domestic sector $i$ required by domestic sector $j$ for each unit of output $x_{j}$ from sector $j$. I is the identity matrix. The $N \times N$ Leontief inverse is defined as $(\mathbf{I}-\mathbf{A})^{-1}$ with elements $b_{i j}$, describing the amount of output generated in each sector $i$ for each unit of final demand for the output of sector $j$.

This standard input-output framework is augmented with a vector of output-pollution coefficients for a single pollutant or a $(K \times N)$ matrix in the presence of $k=1, \ldots, K$ pollutants. Taking the multiple pollutant case, total pollution generation in production is defined as:

$$
\mathbf{f}^{\mathbf{x}}=\mathbf{\Phi} \mathbf{x}
$$

where $\mathbf{f}^{\mathrm{x}}$ is a $K \times 1$ vector, with element $f_{k}^{x}$, where $k=1, \ldots, K$, representing the physical amount of pollutant $k$ generated within the economy through the production of the vector of gross outputs, $\mathbf{x} . \boldsymbol{\Phi}$ is a $K \times N$ matrix where element $\Phi_{\mathrm{k}, \mathrm{i}}$ is the amount of pollutant $k$ per unit of gross output in sector $i$. In the analysis presented here, for simplicity we assume $K=1$, and $k$ is a single pollutant (CO2 in the UK case and NH3 in the US Mid-West case below).

Substituting equation (1) into equation (3) produces:

(4) $\mathbf{f}^{\mathbf{x}}=\boldsymbol{\Phi}(\mathbf{I}-\mathbf{A})^{-1} \mathbf{y}$ 
which relates the $K \times 1$ vector of total pollutants generated in production to the $N \times 1$ vector of final demand.

Turner et al. (2007) extends this single region framework to the case of two or more regions, $r=$ $1, \ldots, R$ and $R=S$ producing and consuming regions. For simplicity of exposition, we state the framework in terms of two regions but it is straightforward to extend to the multi-region case. Now Final demand is presented as a matrix with separate elements for: local final demand in region 1 for commodities produced in region $1\left(\mathbf{y}_{11}\right)$; local (exogenous) final demand in region 2 for commodities produced in region $2\left(\mathbf{y}_{22}\right)$; direct exports to exogenous final demand in region 2 of commodities produced in region $1\left(\mathbf{y}_{12}\right)$ (endogenous intermediate export demand in region 2 for region 1 commodities is given by $\mathbf{A}_{\mathbf{1 2}}$ ); and direct exports to exogenous final demand in region 1 of commodities produced in region $2\left(\mathbf{y}_{21}\right)$. Thus, $\mathbf{x}_{\mathbf{i j}}$ is an $\mathrm{N} \times 1$ vector giving output of sectors in region $i$ generated by the consumption demands (domestic and imports) of region $j$. Equation (1) can therefore be presented for the (2-region) interregional case as:

(5) $\left(\begin{array}{ll}\mathbf{x}_{11} & \mathbf{x}_{12} \\ \mathbf{x}_{21} & \mathbf{x}_{22}\end{array}\right)=\left(\begin{array}{cc}\mathbf{I}-\mathbf{A}_{11} & -\mathbf{A}_{12} \\ -\mathbf{A}_{21} & \mathbf{I}-\mathbf{A}_{22}\end{array}\right)^{-1}\left(\begin{array}{ll}\mathbf{y}_{11} & \mathbf{y}_{12} \\ \mathbf{y}_{21} & \mathbf{y}_{22}\end{array}\right)$

Here, $\mathbf{x}_{\mathrm{rs}}$ is an $\mathrm{N} \times 1$ vector giving output of sectors in region $r$ generated by the consumption demands (domestic and imports) of region $s$.

Each region has $i=1, \ldots, N(=M)=6$ production sectors where each sector $i$ produces only one commodity $j$. Sub-matrices $\mathbf{A}_{\mathbf{r s}}$ therefore contain elements $a_{i j}^{r S}$, describing the transactions between production sector $i$ in producing region $r$ and consuming sector $j$ in consuming region $s$, for each unit output of sector $j$ in region $s .[\mathbf{I}-\mathbf{A}]^{-1}$ is the partitioned interregional Leontief inverse (multiplier matrix). Using a similar notation to that used for the single region model, $b_{i j}^{r s}$ is the output required in 
industry $i$ in region $r$ per monetary unit of final demand for industry $j$ in regions $s$. Thus by partitioning the A-matrix so as to identify intermediate inputs production in the own and other region(s), and by separating the $\mathbf{y}$ vector final demand into commodities produced in the own and other region, it is therefore possible to identify how exogenous demand in one region affects activity in (each) other region.

As for the single region case, this framework can be extended to consider the issue of pollution spillovers between regions. Equation (5) is augmented with $(1 \times N)$ vectors of output-pollution coefficients for a single pollutant $\boldsymbol{\Phi}_{\mathbf{r}}^{\mathbf{x}}$ (again, this could be replaced by a $(K \times N)$ matrix in the presence of $k=1, \ldots, K$ pollutants). Each output-pollution vector shows the direct pollution intensity of output in each production sector $i$ for an individual region, $r$ :

$$
\text { (6) } \begin{aligned}
\left(\begin{array}{cc}
\mathrm{f}_{11}^{\mathrm{x}} & \mathrm{f}_{12}^{\mathrm{x}} \\
\mathrm{f}_{21}^{\mathrm{x}} & \mathrm{f}_{22}^{\mathrm{x}}
\end{array}\right) & =\left(\begin{array}{cc}
\boldsymbol{\Phi}_{1}^{\mathrm{x}} & 0 \\
0 & \boldsymbol{\Phi}_{2}^{\mathrm{x}}
\end{array}\right)\left(\begin{array}{cc}
\mathbf{I}-\mathbf{A}_{11} & -\mathbf{A}_{12} \\
-\mathbf{A}_{21} & \mathbf{I}-\mathbf{A}_{22}
\end{array}\right)^{-1}\left(\begin{array}{ll}
\mathbf{y}_{11} & \mathbf{y}_{12} \\
\mathbf{y}_{21} & \mathbf{y}_{22}
\end{array}\right) \\
= & \left(\begin{array}{ll}
\boldsymbol{\Phi}_{1}^{\mathrm{x}} \mathbf{L}_{11} \mathbf{y}_{11}+\boldsymbol{\Phi}_{1}^{\mathrm{x}} \mathbf{L}_{12} \mathbf{y}_{21} & \boldsymbol{\Phi}_{1}^{\mathrm{x}} \mathbf{L}_{11} \mathbf{y}_{12}+\boldsymbol{\Phi}_{1}^{\mathrm{x}} \mathbf{L}_{12} \mathbf{y}_{22} \\
\boldsymbol{\Phi}_{2}^{\mathrm{x}} \mathbf{L}_{21} \mathbf{y}_{11}+\boldsymbol{\Phi}_{2}^{\mathrm{x}} \mathbf{L}_{22} \mathbf{y}_{21} & \boldsymbol{\Phi}_{2}^{\mathrm{x}} \mathbf{L}_{21} \mathbf{y}_{12}+\boldsymbol{\Phi}_{2}^{\mathrm{x}} \mathbf{L}_{22} \mathbf{y}_{22}
\end{array}\right)
\end{aligned}
$$

The first subscript on each element of Equation (6) identifies the producing region, $r$, and the the consuming region, $s . \mathbf{L}_{\mathrm{rs}}$ is that sub-matrix of the partitioned Leontief inverse that gives the total impact on the output in the producing sectors on region $r$ per unit of final demand for output in region $s . f_{r s}^{x}$ is a scalar representing the amount of pollution generated in production activities in region $r$ to support region $s$ final demand. Thus $\mathbf{f}_{\mathrm{rr}}^{\mathbf{X}}$ tells us the amount of pollution that is used in production activities in region $r$ to support final demand in region $r . \mathbf{f}_{\mathrm{sr}}^{\mathbf{x}}$ is the amount of pollution that is used in production activities in region $s$ to support final demand in region $r$, and so on.

If final consumers also directly generate emissions, these are incorporated with a $1 \times Z$ vector, $\boldsymbol{\Phi}_{r}^{y}$, of coefficients for each final consumption group $z$ in region $r$. Each element $\Phi_{z}^{r}$ describes the physical amount of pollution that is directly generates per unit of final expenditure. Generally, one final 
consumption group, households (hh), generate direct emissions, so $z=h h=1$, and this emissions generation only takes place in the home region. So:

(7) $\left(\begin{array}{cc}f_{1}^{h h} & 0 \\ 0 & f_{2}^{h h}\end{array}\right)=\left(\begin{array}{cc}\Phi_{1}^{h h} & 0 \\ 0 & \Phi_{2}^{h h}\end{array}\right)\left(\begin{array}{cc}y_{1}^{h h} & 0 \\ 0 & y_{2}^{h h}\end{array}\right)$

By summing the partitioned matrices in Equations (6) and (7), it is possible to measure all emissions in regions $r=1, \ldots, R$ that are attributable to final consumption demand in each region for the outputs of the other region(s). For example, total emissions generated in region 1 (emissions generated within region 1 under the production accounting principle, PAP) are found by summing along the first row of each $\mathbf{f}$ matrix so that:

(8) $f_{1}^{x}=f_{11}^{x}+f_{12}^{x}+f_{1}^{h h}$

And total emissions in both regions 1 and 2 that are attributable to region 1 final consumption demand (emissions under the consumption accounting principle, CAP) are found by summing down the first column of each $\mathbf{f}$ matrix so that:

(9) $f_{1}^{y}=f_{11}^{x}+f_{21}^{x}+f_{1}^{h h}$

In accordance with the Munksgaard and Pedersen's (2001) consumption accounting principle, region 1's pollution 'trade balance' with region 2 is calculated as the difference between Equations (8) and (9), and the corresponding calculations for region 2 are carried out using the second row and column of the $\mathbf{f}$ matrices in (6) and (7). This means that the pollution 'trade balance' is given by:

(10) $P T B=f_{r s}^{x}-f_{s r}^{x}$ 
In the framework outlined above, the treatment of interregional trade between regions 1 and 2 is in accordance with the consumption accounting principle, such that total pollution generation within the geo-political area covered by these regions is attributed to consumption demand therein. Thus, if data are available to state the system to encompass all (direct and indirect) trade partners of all regions $r=1, \ldots, R=S$ included, (9) would give the full pollution 'footprint' (e.g. the carbon footprint) of region 1 .

Within the framework outlined above, it is also possible to decompose the structure of the pollution supported by different types of final consumption in each region (household and government consumption and capital formation, as well as any external demands from outwith the system - see below) and the specific sectoral outputs that are consumed (i.e. pollution generation in sector $i$ in region $r$ supported by final consumption group $z$ in region $s$ ).

\subsection{Treatment of external (international) trade}

If all regions/countries that the target region trades (directly or indirectly) with are not accounted for in the system in (6) a decision must be made on how any external trade is dealt with. Generally, inputoutput tables for any target region, $r$, will record export demand from other regions and/or the rest of the world for each sectoral output, $j$, as a column or columns within the $\mathbf{Y}$ matrix. However, this will usually only identify the destination region (e.g. the Scottish input-output tables report two columns for total exports from each production sector to the rest of the UK and the rest of the world respectively), but not the using/consuming sector/final consumption group therein. Moreover, there

will generally be a corresponding row reporting imports from the other region(s), but only in terms of the total value of imports to each sector $i$ and final consumption group, $z$, not the sectoral outputs, $j$, produced in each other region $r$, that are used/consumed.

Where data are available to identify or estimate the full $\boldsymbol{A}_{\boldsymbol{r} s}$ and $\boldsymbol{y}_{\boldsymbol{r} \boldsymbol{s}}$ matrices/vectors, and corresponding 
pollution intensity vectors, $\boldsymbol{\Phi}_{r}^{\boldsymbol{x}}$ (and, where appropriate, $\boldsymbol{\Phi}_{r}^{\boldsymbol{y}}$ ) for trade partners (as has been possible here for Scotland and the rest of the UK, and the five Mid-West states and RUS) equation (6) can be populated and estimates under both PAP and CAP and the corresponding pollution trade balance can be determined using equations (7)-(9). However, as explained by Turner et al. (2007), in the presence of extensive global trade, one is likely to effectively require a world interregional input-output framework, identifying all of the target region's direct and indirect trade partners and differences in production and carbon emitting technologies therein (see also Andrew et al., 2009).

Moreover, even if it were possible to identify such a database to analyse the resource requirements of final consumption in the region of interest, there are also issues relating to jurisdiction and policy concern with regard to different types of pollutant that may make it appropriate and/or desirable to adopt an alternative approach. For example, Turner et al (2011a) argue that one issue with focussing on the CAP measure in (9) decisions regarding production technology and resulting resources used/pollution generated in the regions/countries that the target region directly or indirectly imports from, are likely to lie outwith the jurisdictional authority of government in the region whose consumption behaviour is under examination (on issues of jurisdiction see also Peters and Hertwich, 2008). Therefore they propose an alternative extension of the system in (4) that focuses on uni-directional trade flows (imports to the target region only, dropping exports from final consumption, $\mathbf{y}$, in order to focus on domestic consumption only) but only considering input to production decisions in the target region only, and the pollution technology that would apply if the target region produced all inputs domestically:

(10) $f_{r}^{y}=\Phi_{r}^{x}\left[I-\left(A_{r r}+A_{s r}\right)\right]^{-1}\left(y_{r r}+y_{s r}\right)+\Phi_{r}^{y} y_{r r}^{*}$

(where $*$ denotes a transpose vector, and with total final consumption by each final consumption group, z, generally collapsing to households as in (7) above). The system in (10) requires only data on imports in input-output matrix format in addition to the single region framework in (4) but allows estimation of a CAP measure under a 'domestic technology assumption' (see also Druckman et al, 
2009) that regional policymakers are likely to have more control over. However, here, due to the availability of data provided by colleagues at OECD on the country/region source of UK imports from the rest of the world and corresponding CO2 intensities (see Turner et al, 2011b), along with regionspecific $\mathrm{CO} 2$ data for each region examined, in the empirical analyses reported below we relax the domestic technology assumption to attempt to estimate actual carbon footprints. This involves replacing vector $\Phi_{\mathbf{r}}^{\mathbf{x}}$ with the $1 \times \mathrm{xN}$ vector $\Phi_{\mathbf{W}}^{\mathbf{x}}$, of weighted direct pollution intensities for each commodity output $j$, where the weights attached to the direct carbon intensity of output in each producing country, $r$, given by the share of commodity output $j$ from region/country $r$ in total region $s$ use of commodity output.

Of course (10) does not capture interregional feedback effects or multiplier effects in the region(s) that the target region imports from. Where this is desirable for some sub-set of regions that the target region trades with (for example, for a group of regions within a single national economy), it is possible to utilise both (6) and (10), using the former to consider intra-national trade and the latter for international trade. We adopt a mixed approach for the case of Scotland and the rest of the UK below.

The other issue raised above is that policy concern with regard to different types of pollutants may mean that the full interregional approach applied to all trade as in (6) is not appropriate, desirable or useful. For example, McGregor et al (2008) argue that where national pollution targets under the Kyoto Protocol and/or Copenhagen Accord relate to emissions generation within national borders, it may be appropriate to consider intra-national trade under the consumption accounting principle using (6) but apply the production accounting principle to trade with ROW. This may involve one of two approaches. First, (6) could be calculated including exports to ROW from each region, $r$, within their own pollution account as part of $\mathbf{y}_{\mathrm{rr}}$ and $\mathbf{f}_{\mathrm{rr}}^{\mathbf{x}}$, but with no consideration of the pollution implications of imports. Second, (6) could be adjusted to consider the domestic (rather than global) pollution implications of the region's import requirements by considering the pollution involved in export production that finances imports through the nation's current account. 
McGregor et al (2008) argue in favour of the latter adjustment and develop (6) to give what they refer to as a trade endogenised linear attribution system (TELAS). This is for a national (UK) pollution accounting framework where all regions $r=1, \ldots, \mathrm{R}(=\mathrm{S})$ are regions within that national economy. The TELAS approach (also applied by Turner et al, 2011a, for the single region case of Wales) involves endogenising trade in much the same way as household final consumption is endogenised in a standard Type II analysis (see Miller and Blair, 2009). Instead of including international export demand for each region within the $\mathbf{Y}$ final demand matrix, they create an additional national production sector in the partitioned A-matrix, a Trade sector, $t$, which produces goods for trade to facilitate the imports required in the national economy as a whole. The row entries for each sector $j$ in each (consuming) region $s$ are that sector's imports from ROW as a share of the total input/output, $X_{j}$. The additional column entries are the outputs that must be produced for export to ROW via the trade sector, $t$, by each (producing) sector $i$ per unit of unit of total imports required in the UK economy as a whole (intermediate and final consumption), which is the output of the Trade sector. The pollution intensity of the output of the new national Trade UK trade sector is equal to zero, as no emissions are directly generated here (emissions directly generated in producing output for export demand are generated in the producing sectors and are, therefore, embodied indirectly in intermediate sales to the new trade sector).

Thus, when (6) is calculated for the extended system with trade endogenised, this means that each individual (production or consumption) sector that imports from ROW will be attributed the pollution embodied in the share of total national domestic export production required to finance these imports. Because the production accounting principle is applied at the national level, no attempt is made to estimate the pollution embodied in imports (i.e. pollution generated elsewhere in the world to support regional consumption demands within (6)). Instead, the TELAS approach focuses on pollution generated within the national economy to support consumption therein.

McGregor et al (2008) conduct input-ouput analyses under both PAP and CAP principles for the case of Scotland and the rest of the UK (RUK) in 1999 in a 3-sector (or 4-sector, including Trade, in the 
case of TELAS), 2-region framework. ${ }^{1}$ Below, we update the Scotland-RUK case to 2004 with a 6sector, 2-region framework. However, we do not apply TELAS in the UK case. Instead, with the UK case focusing on the key greenhouse gas $\mathrm{CO} 2$, we consider a CAP application using a combination of (6) and (10). In doing so, we do not make the argument that TELAS would be inappropriate (UK national $\mathrm{CO} 2$ targets are still set in terms of PAP rather than CAP). Rather, we attempt to extend McGregor et al's (2008) analysis to consider the implications if some form of CAP measure were also adopted for the UK. We consider the application of the TELAS approach in a different geographical and policy context. This is the generation of acid rain precursors, the emissions of which, while impacting over relatively large geographical areas, are generally considered in terms of direct emissions within a national context. We consider the case of emissions of a single non-GHG air pollutant, ammonia (NH3), generated mainly as a result of agricultural production activity, the reduction of which is considered to be particularly challenging (Kaiser, 2001) in the context of the US Mid-West. Here we extend on the standard production accounting principle to consider what demand patterns within the US (including demand for imported goods and services) drive levels of agricultural production and pollution therein.

\section{Illustrative case study 1: Accounting for $\mathrm{CO} 2$ generation in and attributable to UK regions under production and consumption accounting principles}

Our first case study is to examine UK CO2 generation in the accounting year of 2004, broken down by 6 production sectors (an aggregation of the 123 SIC-classified input-output categories reported in UK national and regional IO accounting ${ }^{2}$ ) and two regions, Scotland and the rest of the UK, RUK. ${ }^{3}$ In

\footnotetext{
${ }^{1}$ Wiedmann et al. (2010) also estimate UK carbon footprints, but with a focus on the national rather than regional economies and using full multi-region input-output methodology.

${ }^{2}$ Generally, input-output accounting is carried out at a greater degree of sectoral detail than that reported in the case studies here. We opt for a higher level of aggregation in the illustrative case studies primarily to report disaggregated results and explain these to the reader. However, there is a more practical motivation in that the quality of the experimental Scottish Government data on Scottish sectoral emissions is questionable at a greater degree of sectoral disaggregation.

${ }^{3}$ Scotland is the only region of the UK for which official input-output tables are published by a government agency.
} 
the case of Scotland, we draw on the 2004 Scottish input-output tables ${ }^{4}$, along with experimental data on imports from RUK and the rest of the world (ROW) in input-output format and sectoral $\mathrm{CO} 2$ intensity data provided by the Scottish Government input-output team. In the case of the UK, where input-output data are not published in the required analytical format (symmetric tables in producer/basic prices), we draw on data published by Wiedmann et al (2008) to construct our own UK industry-by-industry analytical IO table for $2004 .{ }^{5}$ We augment this with data on imports from ROW in input-output format constructed by Wiedmann et al (2008) and carbon intensity data from the UK environmental accounts. ${ }^{6}$ The interregional framework to populate (5) is then constructed in the manner outlined for 1999 in McGregor et al (2008). RUK sectoral emissions are simply taken as the difference between UK and Scottish emissions at the six sector level and the output-pollution coefficients derived by dividing through by activity levels. See Tables 1 and 2 .

\section{<Insert Tables 1 and 2 around here>}

Table 1 shows that broadly Scottish emissions intensities are not greatly different from the UK averages except in the case of Energy (which includes gas and electricity distribution), where the CO2-intensity of the Scottish sector is significantly lower than the UK average (due to the greater use of renewable electricity generation technologies), and extraction, quarrying, construction and water supply activities, where the Scottish CO2 intensity is markedly higher (largely due to the differential composition of activity in the aggregate sector). Table 2 shows the sectoral generation of $\mathrm{CO} 2$ in at the regional and national level, where just over $8 \%$ of UK emissions are directly generated in Scotland.

However, we can get a better understanding of the regional structure of $\mathrm{CO} 2$ generation, and of the extent of $\mathrm{CO} 2$ "trade" between Scotland and RUK by estimating equation (6) where the A matrix is a

\footnotetext{
${ }^{4}$ Scottish input-output tables for 1998-2007 can be downloaded at http://www.scotland.gov.uk/input-output.

${ }^{5}$ The UK analytical input-output table for 2004 can be downloaded at http://www.strath.ac.uk/fraser/research/2004ukindustry-byindustryanalyticalinput-outputtables/.

${ }^{6}$ The UK environmental accounts for 2004 in input-output format can be downloaded at http://www.statistics.gov.uk/statbase/Product.asp?vlnk=14883\&image. $x=14 \&$ image. $y=9$.
} 
$2 N \times 2 N$, or $12 \times 12$ (with 6 sectors in each region) partitioned matrix where only the outputs of UK production sectors are treated as endogenous, and the partitioned matrix $\mathbf{Y}$ of final consumption demands includes export demand from the rest of the world (ROW). That is, we begin with a conventional Type I (Miller and Blair, 2009) open economy attribution analysis to understand the drivers of UK regional PAP generation (what is accounted for under agreements such as the Kyoto Protocol and Copenhagen Accord).

Table 3 shows the scale of the CO2 "trade" (or "spillovers") that occur between Scotland and the rest of the UK. Of the total $\mathrm{CO} 2$ generated in the UK directly or indirectly as a result of conventional Scottish final demand expenditures, just over 30\% (16.2 million tonnes of $\mathrm{CO} 2$ measured as $\mathrm{CO} 2$ equivalent) is generated in RUK (i.e. not in Scotland). A similar proportion of CO2 generated in Scotland is to support, directly or indirectly, RUK final demand (15.5 million tonnes, just under 30\%). Also note that Scottish exports to the rest of the world, which produce no direct $\mathrm{CO} 2$ outwith Scotland, still 2.6 million tonnes of $\mathrm{CO} 2$ in RUK as a result of the indirect impacts of the production of intermediate inputs.

\section{<Insert Table 3 around here >}

The sectoral distribution of direct $\mathrm{CO} 2$ generation in each region is shown in the final column of Table 3. Along each row, we can see how this breaks down by final consumption demand in each region (including both domestic regional demands and also ROW export demand for each region's output). The largest share of $\mathrm{CO} 2$ embodied in trade flows between the two regions is embodied in trade in Energy sector outputs, which is not surprising given the pollution intensity of this type of production. While Energy production is less CO2-intensive in Scotland (see Table 1), emissions embodied in production to support RUK demands, 8.9 million tonnes (including the 1.7 million tonnes supported by ROW demand for RUK outputs) accounts for just under $17 \%$ of total CO2 emissions in Scotland. Next to Energy, trade in aggregate Manufacturing outputs is the next most 
important accounting for $21 \%$ of CO2 embodied in Scotland to RUK trade and $28 \%$ in the other direction.

At the bottom of Table 3, note that there is a negative $\mathrm{CO} 2$ trade balance for Scotland, implying that the pollution generated in Scotland by production supporting RUK final demands is less than the pollution generated in RUK by production supporting Scottish final demands. However, the Scottish $\mathrm{CO} 2$ trade deficit (-0.7 million tonnes) is relatively small, accounting for just $1.25 \%$ of total $\mathrm{CO} 2$ generated in Scotland. Moreover, Turner et al (2011b) identify how this 'deficit' relationship is driven by the fact that cleaner electricity generation technology in Scotland (incorporated in the Energy sector here) reduces the level of $\mathrm{CO} 2$ embodied in exports to RUK, rather than Scottish imports being particularly CO2-intensive.

However, if we wish to consider $\mathrm{CO} 2$ emissions attributable to regional consumption demands under a full consumption accounting principle, $\mathrm{CO} 2$ embodied in exports (to other UK regions and/or to ROW) should not be included. Rather, if policy and public interest shifts to measuring the "carbon footprint' of rather than just domestic emissions within a region or country, the focus should be focussed on emissions required anywhere in the world to support regional demands. In Table 3 we have used equation (6) to calculate emissions within the UK required to support Scottish consumption (44.4 million tonnes) and RUK consumption (454 million tonnes) respectively. Note that, in removing emissions required to support ROW demands, we have a 'carbon footprint' figure that is less than $\mathrm{CO} 2$ generation under PAP at both regional and national level. However, no account has been taken of emissions embodied in imports from ROW. In Table 4, we use equation (10) to estimate this.

\section{<Insert Table 4 around here $>$}

The first thing to note is that the CAP figures in Table 4 are considerably higher than the PAP figures in Table 3: the Scottish footprint (76 million tonnes) is $44 \%$ larger than its domestic PAP emissions (52.8million tonnes), while the UK footprint (727.4 million tonnes) is $26 \%$ higher (578.3 million 
tonnes). ${ }^{7}$ While Scotland directly generates $40 \%$ of its carbon footprint, in RUK this is higher at $61 \%$. The commodity composition of the two regional footprints is quite varied, with a greater share of the Scottish carbon footprint (33\% compared to $27 \%$ in RUK) originating in Energy production and a greater share of the UK footprint (18.5\% compared to 14\%) in Manufacturing. Direct household emissions are also more important in the RUK case (20\% of the total footprint) than in the Scottish case $(17 \%)$.

To compare in absolute terms, the results may be scaled to reflect the fact that Scotland is a much smaller (as well as a more open economy). In per capita terms the Scottish footprint works out at 15 tonnes per capita (using the 2004 population figure of just over 5 million), which is $13 \%$ larger than the RUK equivalent, 13.3 tonnes (2004 population just under 54.8 million). This contrasts with per capita PAP emissions, which are much closer at 10.4 and 10.6 tonnes per capita in Scotland and RUK respectively. The divergence in 'pollution leakage' impacts of consumption in ROW, the 31.6 million tonnes of $\mathrm{CO} 2$ embodied in ROW imports required to support Scottish consumption equates to 6.2 tonnes per capita, which is $25 \%$ larger than the corresponding RUK figure of 5 tonnes per capita. This is despite the fact that in 2004 Scotland ran a goods and services trade surplus with ROW, in contrast with a deficit at the RUK and UK level. That is, it reflects the composition of Scottish imports from ROW and the corresponding $\mathrm{CO} 2$ intensity.

As Turner et al (2011a) discuss, the issue of whether a shift to CAP rather than PAP measures would be feasible and appropriate is a complex one, given that production technologies (and their pollution intensity) employed in other countries are both difficult to identify accurately and likely to outwith the jurisdiction of regional/national policy makers. However, $\mathrm{CO} 2$ is a greenhouse gas and climate change is a global problem so it would seem appropriate to develop accounting frameworks such as the IO one introduced here to examine CAP emissions at least alongside PAP measures. In the case of

\footnotetext{
${ }^{7}$ Note that throughout the analysis here we use UK Environmental Accounts data that include emissions from UK aviation and shipping.
} 
non-GHG pollutants which have more localised impacts, on the other hand, alternative measures may be more appropriate and informative.

\section{Illustrative case study 2: Accounting for and attributing responsibility for NH3 emissions generation in agricultural production in the US Mid-West}

For example, in the United States, which has tended to focus on voluntary reduction of emissions of non-CO2 greenhouse gases (methane and fluorocarbon emissions) and is not a signatory to the Kyoto Protocol or Copenhagen Accord, much of the federal environmental regulation and policy has focussed on air quality within the US (e.g. the 1970 Clean Air Act, CAA, and the subsequent 1977 and 1990 Clear Air Act Amendments, CAAA, set deadlines for compliance with nationwide ambient air quality standards, NAAQS). Emissions of acid rain precursors ( $\mathrm{SO} 2$ and $\mathrm{NOx}$ ) have received particular focus under the CAAA as well as the Acid Deposition Control Program of 1990 and the Bush administration's Clear Skies Initiative of 2003). Pollution spillover effects are given attention in terms of trans-boundary air pollution issues between the US and Canada in the 1991 Air Quality Agreement, but this also focuses primarily on acid rain precursors, as does the 2005 Clean Air Interstate Rule issued by the US Environmental Protection Agency, which caps emissions of S02 and NOx in the 28 Eastern US states (including the 5 Mid-West states considered here) and in the District of Columbia, which are particularly affected by acidic deposition.

Another air pollutant of significant policy concern in the US is ammonia, or NH3. NH3 emissions may actually neutralise acid rain, or even make it alkaline, but may cause soil acidification through nitrification. As with emissions of the main acid rain precursors ( $\mathrm{SO} 2$ and $\mathrm{NOx}$ ), formation of secondary particulates from NH3 emissions may react with organic compounds to contribute to ozone formation, causing vegetation, material and health damage as well as affecting visibility. (Menz and Seip, 2004.) While NH3 emissions are generated through transport and other industrial activities (for example the US's Comprehensive Environmental Response Compensation Liability Act, CERCLA, of 1980 focuses on emissions from chemical and petroleum industries), the main sources are 
agricultural through livestock operations and the use of fertilisers. We focus on $\mathrm{NH} 3$ here to demonstrate how input-output analysis may be used to understand the structural nature of emissions from a particular sectoral source.

We use the 10-sector, 6-region input-output tables for the Midwest and the rest of the US (RUS) derived using the method of Jackson et al. (2006) from 2007 IMPLAN $^{8}$ US interregional input-output and commodity flow data. See Ha et al (2007) for details. The ouput-NH3 coefficients to populate the $(1 \times N)$ vector $\boldsymbol{\Phi}_{\mathbf{r}}^{\mathbf{x}}$ for each of the five Midwest states accounted for (Illinois, Indiana, Ohio, Michigan and Wisconsin) and RUS are derived from research carried out at the Regional Economics Applications Laboratory, University of Illinois, and funded by the US EPA STAR program (more detailed methodology can be found in Tao et al., 2007). This research also identifies emissions intensities for carbon monoxide (CO), nitrogen oxide (NOx), sulfur dioxide $\left(\mathrm{SO}_{2}\right)$, particular organic compound (PM10 and PM2.5 with diameter less than 10 and $2.5 \mu \mathrm{m})$ and volatile organic compound (VOC). The NH3 intensities (tonnes per $\$ 1$ million sectoral output) are shown in Table 5.

\section{<Insert Table 5 around here >}

Table 5 shows that in all six regions identified the most NH3-intensive activity is Agriculture, Forestry and Fisheries. However, as noted above, it is agricultural production, particularly involving the use of fertilizers and/or livestock operations that is the main source of $\mathrm{NH} 3$ emissions. Note that, with an NH3-intensity of just over 33 tonnes per \$1 million output, the agricultural activity in the state of Wisconsin is the most intensive in the production of this pollutant. This is due to the particular composition of agricultural activity: the Wisconsin profile from the 2007 US Census of Agriculture ${ }^{9}$ shows that Wisconsin is the second largest US producer of 'milk and other dairy products from cows', 'other animals and animal products' as livestock operations, and the largest producer of 'corn for silage', which involves the use of fertilisers.

\footnotetext{
${ }^{8}$ http://implan.com/V4/Index.php

${ }^{9}$ The 2007 Census of Agriculture for the US can be accessed at http://www.agcensus.usda.gov/.
} 
The first numerical column of Table 6 shows the physical amount (in tonnes) of NH3 directly generated in Agriculture (the Agriculture, Forestry and Fisheries sector) relative to the all other sectors (the other nine from Table 5) identified. Note that in all six regions identified at least $80 \%$ of $\mathrm{NH} 3$ emissions are from agricultural sources and in the case of Wisconsin this rises to $98.4 \%$. Policy tends to focus on the direct sources of these emissions. However, as in the case of $\mathrm{CO} 2$ above, inputoutput methods can be used to understand the structure of the pollution generation problem in terms of the sources of demand driving these emissions. Therefore in Table 3 we apply equation (6) for the $\mathrm{R}=\mathrm{S}=6$ region, $\mathrm{N}=10$ sector case to attribute $\mathrm{NH} 3$ emissions to exogenous final demands originating in each of the 5 Midwest states, RUS and ROW.

\section{$<$ Insert Table 6 around here >}

Taking the example of agricultural emissions in Wisconsin, reading along the row the Type I inputoutput analysis shows that, in the accounting year of $2007,34.3 \%$ of emissions are attributable to own-region final consumption demands, $16.8 \%$ to final consumption in other Midwest states, $27.8 \%$ to other US and $19.4 \%$ to consumption demand outside the US. In interregional trade balance terms within the US (and taking results for both agricultural and non-agricultural emissions), the amount of NH3 embodied in imports from other US states (other Midwest plus RUS) underlying the $2.7 \%$ of total US NH3 (173,577 tonnes) supported by Wisconsin final consumption is only around a third (50,893 tonnes) of that embodied in exports to other Midwest and RUS states (156,898 tonnes).

\section{<Insert Table 7 around here $>$}

However, in understanding the structure of the NH3 problem, and the nature of the economic activity that gives rise to it, perhaps the most interesting result is that a large share $(19.6 \%)$ of $\mathrm{NH} 3$ generated in Wisconsin, and just under $20 \%$ of agricultural emissions, is supported by consumption demand outside the US. In this respect, reading down the second last column of Table 6 , observe that 
Wisconsin has the lowest share of its NH3 emissions supported by external ROW demands. However, Table 7 shows that Wisconsin overall import requirement relative to its export production is also relatively low. That is, it exports far more (with a value of $\$ 37.5$ billion in 2007 , of which $27.4 \%$ were from the Agriculture, Forestry and Fisheries sector, the highest share across the states in Table 7) than it required to finance its own imports (which were valued at $\$ 13.7 \mathrm{billion}$ ). It is in this context that the TELAS approach discussed above may prove useful. In Table 8 we repeat the analysis using equation (6), but this time endogenise trade with the rest of the world under the assumption that exports (inputs to a new US-level 'Trade' sector) are produced in order to finance or facilitate imports (the output of the new Trade sector) to support final consumption demands within the US.

\section{<Insert Table 8 around here >}

The results in Table 8 reflect the fact that all five Midwest states have relatively low import to export ratios. In Table 8 the $\mathrm{NH} 3$ emissions in each region that are attributed to ROW in the Type I analysis in Table 6 are essentially reallocated pro rata to the sectors and final consumers in each region that import. From this viewpoint, the cost of imports, both in economic and environmental terms (with the latter focussing here on $\mathrm{NH} 3$ emissions), is the examined in terms of cost and environmental damage (e.g. soil acidification) associated with the exports that production sectors in each region have to provide to pay for US imports. Again taking the example of the Wisconsin agriculture row, if we compare the results in Tables 6 and 8, observe that while there are small increases in the percentage of emissions attributable to each of the Midwest states, the largest increase (from 27.8\% to 44.6\%) is in NH3 emissions generated in Wisconsin that are attributable to consumption demand in RUS. That is, almost half of $\mathrm{NH} 3$ emissions produced in this state are required to support final consumption activity (including imports) in the non-Midwest states. Similar increases and magnitudes for NH3 emissions supported by RUS consumption are observed across all five Midwest states.

In the case of a more localised pollutant like $\mathrm{NH} 3$, where environmental impacts such as soil acidification will be felt locally (and impact on the future economic costs of carrying out production 
activities), demand path analysis of the type that is facilitated particularly by the TELAS approach would seem to be of potential usefulness to policymakers. That is, the results in Table 6 suggest that the Midwest states are bearing a more than proportionate environmental cost (in terms of the impacts of a damaging agricultural pollutant) of consumption activity within the US as a whole. It may be quite rightly argued that the Midwest states are producing and trading based on their comparative (and resource) advantage in agriculture. However, the findings raise questions in terms of who should bear the costs of environmental damage in particular areas of the US to support consumption demands in the nation as a whole.

\section{Discussion and conclusions}

This paper uses input-output accounting methods to consider issues of pollution attribution from different accounting perspectives that may be useful to regional and national policymakers in considering climate change and other environmental policy objectives.

Input-output accounting techniques are already accepted, particularly in the economic systems and ecological economics literature as providing appropriate methods to track pollution embodied in complex economic interactions and supply chains. However, to date most applications have focussed on case studies for national economies and international trade. In the research reported here we take a more sub-national/regional level focus and consider what may be achieved using currently available/accessible data to provide analysis and results that may be useful in different jurisdictional contexts and with respect to different pollutants.

In the UK case study reported we focus on moving towards a full consumption accounting perspective for the main greenhouse gas, $\mathrm{CO}$, but using analytical techniques that could be applied to any greenhouse gas or other pollutant. However, in our US case study, where there is less policy focus on climate change issues, we consider what input-output accounting methods may offer in considering pollutants with more localised effects. We focus on agricultural pollution in the Midwest states 
(taking the example of ammonia, NH3), but our analysis using the TELAS technique may have wider applicability where concern is on domestic pollution generation. Here we argue that it may be useful to move away from focussing solely on the production source of pollutants to consider the domestic consumption demands that ultimately drive polluting activity in the context of accounting for the full domestic resource costs of domestic consumption behaviour.

We close with two notes of caution and priorities for future research. First, as has been highlighted throughout this paper, there are issues of data availability for, particularly consumption-focussed, pollution accounting. This problem is not limited to input-output analysis and there is a need for research and policy communities to come together to identify and prioritise needs in economyenvironment accounting in general (for example consistent reporting classifications for economic and environmental data; consistency in reporting across trading nations/regions; availability of detailed bilateral trade data).

Second, input-output techniques are invaluable in accounting for and understanding the structure of pollution problems in a given time frame (that which input-output accounts are reported for). However, the next step in policy analysis may be to consider the impacts of changes in economic activity on various pollution measures. As an accounting framework, input-output tables and inputoutput demand-driven multiplier techniques are absolutely appropriate for conventional pollution attribution analyses because they provide all the required information on pollution embodied in intersectoral interactions and interregional trade flows. However, as a model of how the economy moves from one equilibrium to another in response to a marginal change in activity, input-output is unlikely to be appropriate because it is only a very special case of a wider set of general equilibrium approaches. Where there is a need to model the impacts of changes in activity, particularly where there are likely to be changes in supply-side behaviour, it is appropriate to consider more flexible and theory-consistent approaches, such as the sider set computable general equilibrium techniques of which input-output provides a limiting case (see, for example, Bergman, 2005, for a review). 


\section{References}

Andrew R, Peters G, Lennox J, 2009 "Approximation and regional aggregation in multi-regional input-output analysis" Economic Systems Research 21 311-335

Bastianoni S, Pulselli FM, Tiezzi E, 2004, "The problem of assigning responsibility for greenhouse gas emissions" Ecological Economics 49 253-257

Bergman L, 2005, "CGE Modelling of Environmental Policy and Resource Management" in: Handbook of Environmental Economics: Economy wide and International Environmental Issues Eds K-G Mäler and J Vincent (Elsevier, North Holland) pp 1273-1306

Druckman A, Jackson T, 2009 "The carbon footprint of UK households 1990-2004: A socioeconomically disaggregated, quasi-multi-regional input-output model" Ecological Economics 68 2066-2077

Ferng JJ, 2003, "Allocating the responsibility of CO2 over-emissions from the perspectives of benefit principle and ecological deficit" Ecological Economics 46 121-141

Ha, SJ, Hewings G, Turner, K. 2009 "An interregional input-output analysis of the pollution content of trade flow and environmental trade balances between five states in the US Midwest" Strathclyde Discussion Papers in Economics 09-20.

Hoekstra R, Janssen MA, 2006, "Environmental responsibility and policy in a two-country dynamic input-output model" Economic Systems Research 18 61-84

Jackson RW, Schwarm WR, Okuyama Y, Islam, S, 2006 "A method for constructing commodity by industry flow matrices" The Annals of Regional Science 40 909-920.

Kaiser, J, 2001 “The other global pollutant: nitrogen proves tough to curb” Science 294, 268-269

Kondo Y, Moriguchi Y, Shimizu H, 1998, "CO2 Emissions in Japan. Influences of Imports and Exports" Applied Energy 59 163-174

Leontief W, 1970, "Environmental repercussions and the economic structure: an input-output approach" Review of Economic and Statistics 52 262-277 
Mongelli I, Tassielli G, Notarnicola B, 2006, "Global warming agreements, international trade and energy/carbon embodiments: an input-output approach to the Italian case" Energy Policy 34 88-100

Munksgaard J, Pedersen, KA, 2001, “CO2 accounts for open economies: producer or consumer responsibility?" Energy Policy 29 327-334

Peters G, Hertwich E, 2008, "CO2 embodied in international trade with implications for global climate policy" Environmental Science and Technology 42 1401-1407

McGregor P, Swales J, Turner K, 2008, "The $\mathrm{CO}_{2}$ trade balance between Scotland and the rest of the UK: performing a multi-regional environmental input-output analysis with limited data" Ecological Economics 66 662-673

Menz FC, Seip HM, 2004, “Acid rain in Europe and the United States: an update” Environmental Science and Policy 7 253-265

Miller R, Blair P, 2009, Input-Output Analysis: Foundations and Extensions $2^{\text {nd }}$ ed (Cambridge University Press, Cambridge)

Sánchez-Chóliz J, Duarte R, 2004, "CO2 emissions embodied in international trade: evidence for Spain” Energy Policy 32 1999-2005

Tao Z, Williams A, Donaghy K, Hewings G, 2007, A socio-economic method for estimating future air pollutant emissions-Chicago case study, Atmospheric Environment 41 5398-5409

Turner K, Lenzen M, Wiedmann T, Barrett J, 2007, "Examining the Global Environmental Impact of Regional Consumption Activities - Part 1: A Technical Note on Combining Input-Output and Ecological Footprint Analysis" Ecological Economics 62 37-44

Turner, K, Munday, M, Jensen, C.D., McIntyre, S, 2011a, "Incorporating jurisdiction issues into regional carbon accounts under production and consumption accounting principles", forthcoming in Environment and Planning A.

Turner, K, Yamano N, Druckman A, Ha S, De Fence J, McIntyre S, Munday M, 2011b, “An inputoutput carbon accounting tool with carbon footprints estimates for the UK and Scotland", Fraser of Allander Institute Economic Commentary, Special edition, January, 6-20 
Wiedmann T, Lenzen M, Barrett J, Turner K, 2007, "Examining the Global Environmental Impact of Regional Consumption Activities - Part 2: Review of input-output models for the assessment of environmental impacts embodied in trade" Ecological Economics 61 15-26

Wiedmann T, 2009 "Editorial: Carbon footprint and input-output analysis: an introduction" Economic Systems Research 21 175-186

Wiedmann T, Wood R, Lenzen M, Minx J, Guan D, Barrett J, 2008, Development of an embedded carbon emissions indicator - Producing a time series of Input-Output tables and embedded carbon dioxide emissions for the UK using a MRIO Data Optimisation System. Report to the UK Department for Environment Food and Rural Affairs, Stockholm Environment Institute \& Centre for Integrated Sustainability Analysis at University of Sydney

Wiedmann T, Wood R, Lenzen M, Minx J, Guan D, Barrett J, 2010 "The carbon footprint of the UK Results from a Multi-Region Input-Output model” Economic Systems Research 22 19-42.

Wyckoff AW, Roop JM, 1994, "The embodiment of carbon in imports of manufactured products: Implications for international agreements on greenhouse gas emissions" Energy Policy 22 187-194 


\section{TABLES}

Table 1. Output-CO2 coefficients (production sectors) and household final expenditure-C02 pollution coefficients for UK, RUK and Scotland 2004

\begin{tabular}{|c|c|c|c|}
\hline \multirow[b]{2}{*}{ Region } & \multicolumn{3}{|c|}{ Tonnes of $\mathrm{CO} 2$ (equivalent) per £1million output/final demand expenditure } \\
\hline & UK & RUK & Scotland \\
\hline \multicolumn{4}{|l|}{ Sector } \\
\hline 1 Energy & 3081 & 3219 & 2194 \\
\hline 2 Extraction, Quarrying, Construction and Water Supply & 170 & 162 & 257 \\
\hline 3 Agriculture \& Fishing & 282 & 281 & 290 \\
\hline 4 Manufacturing & 230 & 231 & 217 \\
\hline 5 Retail, Distribution and Transport & 233 & 234 & 223 \\
\hline 6 Other services & 30 & 30 & 29 \\
\hline Direct emissions by households & 233 & 233 & 233 \\
\hline
\end{tabular}

Table 2. Direct CO2 Emissions Generated in UK, RUK and Scotland in 2004

\begin{tabular}{|l|r|r|r|}
\hline \multicolumn{2}{|c|}{ Tonnes, millions, of direct CO2 emissions } \\
\hline Sector & UK & RUK & Scotland \\
\hline 1. Energy & 201.5 & 182.2 & 19.2 \\
2. Extraction, Quarrying, Construction and Water Supply & 34.9 & 30.9 & 4.0 \\
3. Agriculture \& Fishing & 6.5 & 5.5 & 1.0 \\
4. Manufacturing & 90.4 & 84.1 & 6.3 \\
5. Retail, Distribution and Transport & 111.3 & 104.3 & 7.0 \\
6. Other services & 29.0 & 26.6 & 2.4 \\
Direct emissions by households & 157.5 & 144.6 & 12.8 \\
\hline TOTAL & 631.1 & 578.3 & 52.8 \\
Direct contribution to UK emissions & $100 \%$ & $91.64 \%$ & $8.36 \%$ \\
\hline
\end{tabular}


Table 3. The CO2 Trade Balance Between Scotland and RUK (tonnes, millions) - Type I Input-Output attribution analysis

\begin{tabular}{|c|c|c|c|c|c|}
\hline Pollution generated in: & $\begin{array}{l}\text { Pollution supported by: } \\
\text { Scottish HH/GOVT/CAPITAL }\end{array}$ & Scot-ROW & RUK HH/GOVT/CAPITAL & RUK-ROW & $\begin{array}{c}\text { Total regional } \\
\text { emissions of } \mathrm{CO} 2 \\
\end{array}$ \\
\hline \multicolumn{6}{|l|}{\begin{tabular}{|l|} 
Scotland \\
\end{tabular}} \\
\hline 1. Energy & $7.7(14.5 \%)$ & $2.7(5.1 \%)$ & $7.2(13.6 \%)$ & $1.7(3.3 \%)$ & $19.2(36.5 \%)$ \\
\hline 2. Extraction, Quarrying, Construction and Water Supply & $2.6(4.8 \%)$ & $0.3(0.6 \%)$ & $1.0(1.8 \%)$ & $0.2(0.4 \%)$ & $4.0(7.6 \%)$ \\
\hline 3. Agriculture \& Fishing & $0.3(0.6 \%)$ & $0.2(0.5 \%)$ & $0.4(0.7 \%)$ & $0.1(0.2 \%)$ & $1.0(2.0 \%)$ \\
\hline 4. Manufacturing & $0.8(1.6 \%)$ & $2.3(4.4 \%)$ & $2.5(4.7 \%)$ & $0.7(1.3 \%)$ & $6.3(11.9 \%)$ \\
\hline 5. Retail, Distribution and Transport & $5.0(9.4 \%)$ & $0.7(1.3 \%)$ & $1.1(2.2 \%)$ & $0.2(0.4 \%)$ & $7.0(13.2 \%)$ \\
\hline 6. Other services & $1.7(3.3 \%)$ & $0.1(0.3 \%)$ & $0.5(0.9 \%)$ & $0.1(0.1 \%)$ & $2.4(4.6 \%)$ \\
\hline Direct $\mathrm{CO} 2$ generation by Scottish households & $12.8(24.3 \%)$ & & & & $12.8(24.3 \%)$ \\
\hline Total CO2 generation in Scotland & $30.9(58.5 \%)$ & $6.4(12.1 \%)$ & $12.5(23.8 \%)$ & $3.0(5.6 \%)$ & $52.8(100 \%)$ \\
\hline \multicolumn{6}{|l|}{ RUK } \\
\hline 1. Energy & $6.5(1.1 \%)$ & $1.7(0.3 \%)$ & $119.8(20.7 \%)$ & $54.2(9.4 \%)$ & $182.2(31.5 \%)$ \\
\hline 2. Extraction, Quarrying, Construction and Water Supply & $0.6(0.1 \%)$ & $0.1(0.01 \%)$ & $25.7(4.4 \%)$ & $4.6(0.8 \%)$ & $30.9(5.3 \%)$ \\
\hline 3. Agriculture \& Fishing & $0.2(0.03 \%)$ & $0.1(0.01 \%)$ & $4.0(0.7 \%)$ & $1.2(0.2 \%)$ & $5.5(0.9 \%)$ \\
\hline 4. Manufacturing & $4.0(0.7 \%)$ & $0.5(0.1 \%)$ & $40.8(7.1 \%)$ & $38.8(6.7 \%)$ & $84.1(14.6 \%)$ \\
\hline 5. Retail, Distribution and Transport & $1.9(0.3 \%)$ & $0.2(0.04 \%)$ & $84.5(14.6 \%)$ & $17.7(3.1 \%)$ & $104.3(18.0 \%)$ \\
\hline 6. Other services & $0.4(0.1 \%)$ & $0.1(0.01 \%)$ & $21.9(3.8 \%)$ & $4.2(0.7 \%)$ & $26.6(4.6 \%)$ \\
\hline Direct $\mathrm{CO} 2$ generation by RUK households & & & $144.6(25.0 \%)$ & & $144.6(25.0 \%)$ \\
\hline Total CO2 generation in RUK & $13.5(2.3 \%)$ & $2.6(0.5 \%)$ & $441.5(76.3 \%)$ & $120.7(20.9 \%)$ & $578.3(100 \%)$ \\
\hline Total (UK) CO2 emissions supported by & $44.4(7.0 \%)$ & $9.0(1.4 \%)$ & $454.0(71.9 \%)$ & $123.6(19.6 \%)$ & $631.1(100 \%)$ \\
\hline
\end{tabular}

Pollution trade balance

Scot pollution supported by RUK final demand 
Table 4. Regional carbon footprint estimates for Scotland and RUK (2004) - broken down by composition of Scottish, RUK and ROW commodities directly or indirectly consumed )

\begin{tabular}{|c|c|c|c|c|}
\hline \multirow[b]{2}{*}{ Scotland } & \multicolumn{3}{|c|}{$\begin{array}{l}\text { Carbon footprint by commodity source in each } \\
\text { region (tonnes, millions) }\end{array}$} & \multirow[b]{2}{*}{$\begin{array}{l}\text { Total carbon footprint } \\
\text { by commodity source }\end{array}$} \\
\hline & $\begin{array}{c}\text { Scottish } \\
\text { commodities }\end{array}$ & $\begin{array}{c}\text { RUK } \\
\text { commodities }\end{array}$ & $\begin{array}{c}\text { ROW } \\
\text { commodities }\end{array}$ & \\
\hline 1. Energy & $7.7(10.1 \%)$ & $6.5(8.5 \%)$ & $10.7(14.1 \%)$ & $24.8(32.7 \%)$ \\
\hline 2. Extraction, Quarrying, Construction and Water Supply & $2.6(3.4 \%)$ & $0.6(0.7 \%)$ & $0.6(0.8 \%)$ & $3.8(4.9 \%)$ \\
\hline 3. Agriculture \& Fishing & $0.3(0.4 \%)$ & $0.2(0.3 \%)$ & $0.9(1.2 \%)$ & $1.5(1.9 \%)$ \\
\hline 4. Manufacturing & $0.8(1.1 \%)$ & $4.0(5.2 \%)$ & $5.9(7.8 \%)$ & $10.7(14.1 \%)$ \\
\hline 5. Retail, Distribution and Transport & $5.0(6.5 \%)$ & $1.9(2.5 \%)$ & $12.9(17.0 \%)$ & $19.8(26.0 \%)$ \\
\hline 6. Other services & $1.7(2.3 \%)$ & $0.4(0.5 \%)$ & $0.5(0.7 \%)$ & $2.7(3.5 \%)$ \\
\hline Indirect $\mathrm{CO} 2$ embodied in consumption & $18.1(23.8 \%)$ & $13.5(17.8 \%)$ & $31.6(41.6 \%)$ & $63.2(83.2 \%)$ \\
\hline Direct $\mathrm{CO} 2$ generation by final consumers & $12.8(16.8 \%)$ & & & $12.8(16.8 \%)$ \\
\hline Total carbon footprint (by regional source) & $30.9(40.7 \%)$ & $13.5(17.8 \%)$ & $31.6(41.6 \%)$ & $76.0(100 \%)$ \\
\hline
\end{tabular}

\begin{tabular}{|c|c|c|c|c|}
\hline \multirow[b]{2}{*}{ RUK } & \multicolumn{3}{|c|}{$\begin{array}{l}\text { Carbon footprint by commodity source in each } \\
\text { region (tonnes, millions) }\end{array}$} & \multirow[b]{2}{*}{$\begin{array}{l}\text { Total carbon footprint } \\
\text { by commodity source }\end{array}$} \\
\hline & $\begin{array}{c}\text { Scottish } \\
\text { commodities }\end{array}$ & $\begin{array}{c}\text { RUK } \\
\text { commodities }\end{array}$ & $\begin{array}{c}\text { ROW } \\
\text { commodities }\end{array}$ & \\
\hline 1. Energy & $7.2(1.0 \%)$ & $119.8(16.5 \%)$ & $70.8(9.7 \%)$ & $197.8(27.2 \%)$ \\
\hline 2. Extraction, Quarrying, Construction and Water Supply & $1.0(0.1 \%)$ & $25.7(3.5 \%)$ & $9.4(1.3 \%)$ & $36.0(5.0 \%)$ \\
\hline 3. Agriculture \& Fishing & $0.4(0.05 \%)$ & $4.0(0.6 \%)$ & $11.2(1.5 \%)$ & $15.6(2.1 \%)$ \\
\hline 4. Manufacturing & $2.5(0.3 \%)$ & $40.8(5.6 \%)$ & $90.9(12.5 \%)$ & $134.2(18.5 \%)$ \\
\hline 5. Retail, Distribution and Transport & $1.1(0.2 \%)$ & $84.5(11.6 \%)$ & $82.9(11.4 \%)$ & $168.6(23.2 \%)$ \\
\hline 6. Other services & $0.5(0.1 \%)$ & $21.9(3.0 \%)$ & $8.1(1.1 \%)$ & $30.5(4.2 \%)$ \\
\hline Indirect $\mathrm{CO} 2$ embodied in consumption & $12.5(1.7 \%)$ & $296.8(40.8 \%)$ & $273.4(37.6 \%)$ & $582.8(80.1 \%)$ \\
\hline Direct $\mathrm{CO} 2$ generation by final consumers & & $144.6(19.9 \%)$ & & $144.6(19.9 \%)$ \\
\hline Total carbon footprint (by regional source) & $12.5(1.7 \%)$ & $441.5(60.7 \%)$ & $273.4(37.6 \%)$ & $727.4(100 \%)$ \\
\hline
\end{tabular}

Table 5. Output-NH3 coefficients (production sectors) for US, RUS and 5 Mid-West states (2007)

\begin{tabular}{|r|l|r|r|r|r|r|r|r|}
\hline & & \multicolumn{7}{|c|}{ Tonnes of NH3 per \$1million output } \\
\cline { 3 - 8 } Region & & \multicolumn{1}{|c|}{ US } & \multicolumn{1}{|c|}{ RUS } & \multicolumn{1}{c|}{ Illinois } & Indiana & Michigan & \multicolumn{1}{c|}{ Ohio } & Wisconsin \\
\hline Sector & & & & & & & \\
1 & Agriculture, Forestry and Fisheries & 16.31 & 15.98 & 11.29 & 18.95 & 17.40 & 11.81 & 33.10 \\
2 & Mining & 0.04 & 0.05 & 0.00 & 0.00 & 0.00 & 0.00 & 0.00 \\
3 & Construction & 0.00 & 0.00 & 0.00 & 0.00 & 0.00 & 0.00 & 0.00 \\
4 & Food and Kindred Products & 0.01 & 0.01 & 0.00 & 0.00 & 0.00 & 0.00 & 0.00 \\
5 & Chemicals and Allied Products & 0.07 & 0.09 & 0.00 & 0.00 & 0.00 & 0.01 & 0.00 \\
6 & Metal Manufacturing & 0.02 & 0.02 & 0.01 & 0.04 & 0.00 & 0.01 & 0.00 \\
7 & Industrial Machinery and Electrical & 0.01 & 0.00 & 0.00 & 0.00 & 0.01 & 0.00 \\
8 & Other Non-durable Manufacturing & 0.02 & 0.03 & 0.02 & 0.04 & 0.01 & 0.02 & 0.02 \\
9 & Other Durable Manufacturing & 0.01 & 0.01 & 0.02 & 0.00 & 0.00 & 0.00 & 0.00 \\
10 & TCU, Service, and Government Enterprises & 0.01 & 0.01 & 0.04 & 0.02 & 0.02 & 0.02 & 0.02 \\
\hline
\end{tabular}


Table 6. NH3 Emissions generated in Mid-West regions and RUS attributed under a Type I input-output analysis

\begin{tabular}{|c|c|c|c|c|c|c|c|c|c|}
\hline \multirow[b]{2}{*}{ Pollution generated in: } & \multirow[b]{2}{*}{ Total NH3 emissions (tonnes) } & \multicolumn{7}{|c|}{ Pollution supported by: (percentage of regional total NH3 emissions) } & \multirow[b]{2}{*}{ Total } \\
\hline & & I_FD & J_FD & M_FD & O_FD & W_FD & RUS_FD & Export ROW & \\
\hline Illinois & $\begin{array}{r}173,650 \\
\end{array}$ & & & & & & & & \\
\hline 1. Agriculture & 139,328 & $9.7 \%$ & $2.8 \%$ & $2.3 \%$ & $2.1 \%$ & $1.2 \%$ & $27.9 \%$ & $34.2 \%$ & $80.2 \%$ \\
\hline 2. All other sectors & 34,321 & $11.6 \%$ & $0.4 \%$ & $0.4 \%$ & $0.3 \%$ & $0.3 \%$ & $5.0 \%$ & $1.8 \%$ & $19.8 \%$ \\
\hline Indiana & 173,962 & & & & & & & & \\
\hline 1. Agriculture & 166,173 & $7.1 \%$ & $14.5 \%$ & $3.7 \%$ & $6.0 \%$ & $0.9 \%$ & $27.7 \%$ & $35.7 \%$ & $95.5 \%$ \\
\hline 2. All other sectors & 7,789 & $0.2 \%$ & $2.2 \%$ & $0.1 \%$ & $0.2 \%$ & $0.0 \%$ & $1.1 \%$ & $0.7 \%$ & $4.5 \%$ \\
\hline Michigan & 136,409 & & & & & & & & \\
\hline 1. Agriculture & 125,636 & $3.5 \%$ & $2.3 \%$ & $34.8 \%$ & $5.8 \%$ & $2.0 \%$ & $22.1 \%$ & $21.4 \%$ & $92.1 \%$ \\
\hline 2. All other sectors & 10,774 & $0.2 \%$ & $0.1 \%$ & $5.0 \%$ & $0.3 \%$ & $0.2 \%$ & $1.4 \%$ & $0.7 \%$ & $7.9 \%$ \\
\hline Ohio & 110,127 & & & & & & & & \\
\hline 1. Agriculture & 97,000 & $2.2 \%$ & $2.8 \%$ & $4.3 \%$ & $29.5 \%$ & $0.4 \%$ & $22.0 \%$ & $26.8 \%$ & $88.1 \%$ \\
\hline 2. All other sectors & 13,128 & $0.2 \%$ & $0.3 \%$ & $0.5 \%$ & $6.5 \%$ & $0.1 \%$ & $2.9 \%$ & $1.5 \%$ & $11.9 \%$ \\
\hline Wisconsin & 347,632 & & & & & & & & \\
\hline 1. Agriculture & 341,936 & $6.1 \%$ & $1.3 \%$ & $7.8 \%$ & $1.7 \%$ & $34.3 \%$ & $27.8 \%$ & $19.4 \%$ & $98.4 \%$ \\
\hline 2. All other sectors & 5,696 & $0.1 \%$ & $0.0 \%$ & $0.1 \%$ & $0.0 \%$ & $1.0 \%$ & $0.3 \%$ & $0.2 \%$ & $1.6 \%$ \\
\hline RUS & $5,542,104$ & & & & & & & & \\
\hline 1. Agriculture & $5,187,270$ & $3.0 \%$ & $1.2 \%$ & $1.6 \%$ & $2.1 \%$ & $0.7 \%$ & $64.3 \%$ & $20.7 \%$ & $93.6 \%$ \\
\hline 2. All other sectors & 354,834 & $0.1 \%$ & $0.0 \%$ & $0.1 \%$ & $0.1 \%$ & $0.0 \%$ & $5.1 \%$ & $0.9 \%$ & $6.4 \%$ \\
\hline Total US NH3 emissions & $6,483,885$ & $3.8 \%$ & $1.8 \%$ & $2.9 \%$ & $3.0 \%$ & $2.7 \%$ & $63.4 \%$ & $22.4 \%$ & $100.0 \%$ \\
\hline
\end{tabular}

Table 7. State level trade balances with ROW in 2007 (\$million)

\begin{tabular}{|c|c|c|c|c|c|}
\hline & Exports to ROW & $\begin{array}{c}\text { Of which } \\
\text { agricultural }\end{array}$ & Imports from ROW & $\begin{array}{c}\text { Trade surplus with } \\
\text { ROW }\end{array}$ & $\begin{array}{c}\text { Ratio imports to } \\
\text { exports }\end{array}$ \\
\hline Illinois & 73,809 & $5.7 \%$ & 25,108 & 48,702 & 0.34 \\
\hline Indiana & 45,291 & $19.3 \%$ & 22,109 & 23,182 & 0.49 \\
\hline Michigan & 55,080 & $13.0 \%$ & 36,588 & 18,491 & 0.66 \\
\hline Ohio & 69,355 & $11.8 \%$ & 28,875 & 40,480 & 0.42 \\
\hline Wisconsin & 37,508 & $27.4 \%$ & 13,707 & 23,802 & 0.37 \\
\hline RUS & $1,267,269$ & $25.5 \%$ & $1,133,136$ & 134,133 & 0.89 \\
\hline
\end{tabular}

Table 8. NH3 Emissions generated in Mid-West regions and RUS attributed under a TELAS input-output analysis

\begin{tabular}{|c|c|c|c|c|c|c|c|c|}
\hline \multirow[b]{2}{*}{ Pollution generated in: } & \multirow[b]{2}{*}{ Total NH3 emissions (tonnes) } & \multicolumn{6}{|c|}{ Pollution supported by: (pe rcentage of regional total NH3 emissions ) } & \multirow[b]{2}{*}{ Total } \\
\hline & & I_FD & J_FD & M_FD & O_FD & W_FD & RUS_FD & \\
\hline Illinois & 173,650 & & & & & & & \\
\hline 1. Agriculture & 139,328 & $10.8 \%$ & $3.5 \%$ & $3.6 \%$ & $3.2 \%$ & $1.8 \%$ & $57.3 \%$ & $80.2 \%$ \\
\hline 2. All other sectors & 34,321 & $11.6 \%$ & $0.4 \%$ & $0.5 \%$ & $0.4 \%$ & $0.3 \%$ & $6.5 \%$ & $19.8 \%$ \\
\hline Indiana & 173,962 & & & & & & & \\
\hline 1. Agriculture & 166,173 & $8.2 \%$ & $15.2 \%$ & $5.1 \%$ & $7.1 \%$ & $1.5 \%$ & $58.4 \%$ & $95.5 \%$ \\
\hline 2. All other sectors & 7,789 & $0.2 \%$ & $2.2 \%$ & $0.1 \%$ & $0.2 \%$ & $0.1 \%$ & $1.7 \%$ & $4.5 \%$ \\
\hline Michigan & 136,409 & & & & & & & \\
\hline 1. Agriculture & 125,636 & $4.2 \%$ & $2.8 \%$ & $35.7 \%$ & $6.5 \%$ & $2.4 \%$ & $40.6 \%$ & $92.1 \%$ \\
\hline 2. All other sectors & 10,774 & $0.2 \%$ & $0.1 \%$ & $5.0 \%$ & $0.4 \%$ & $0.2 \%$ & $2.0 \%$ & $7.9 \%$ \\
\hline Ohio & 110,127 & & & & & & & \\
\hline 1. Agriculture & 97,000 & $3.0 \%$ & $3.4 \%$ & $5.4 \%$ & $30.3 \%$ & $0.9 \%$ & $45.1 \%$ & $88.1 \%$ \\
\hline 2. All other sectors & 13,128 & $0.3 \%$ & $0.3 \%$ & $0.5 \%$ & $6.5 \%$ & $0.1 \%$ & $4.2 \%$ & $11.9 \%$ \\
\hline Wisconsin & 347,632 & & & & & & & \\
\hline 1. Agriculture & 341,936 & $6.7 \%$ & $1.7 \%$ & $8.5 \%$ & $2.3 \%$ & $34.6 \%$ & $44.6 \%$ & $98.4 \%$ \\
\hline 2. All other sectors & 5,696 & $0.1 \%$ & $0.0 \%$ & $0.1 \%$ & $0.0 \%$ & $1.0 \%$ & $0.5 \%$ & $1.6 \%$ \\
\hline RUS & $5,542,104$ & & & & & & & \\
\hline 1. Agriculture & $5,187,270$ & $3.6 \%$ & $1.6 \%$ & $2.4 \%$ & $2.8 \%$ & $1.1 \%$ & $82.1 \%$ & $93.6 \%$ \\
\hline 2. All other sectors & 354,834 & $0.1 \%$ & $0.1 \%$ & $0.1 \%$ & $0.1 \%$ & $0.1 \%$ & $5.9 \%$ & $6.4 \%$ \\
\hline Total US NH3 emissions & $6,483,885$ & $4.6 \%$ & $2.2 \%$ & $3.8 \%$ & $3.7 \%$ & $3.0 \%$ & $82.7 \%$ & $100.0 \%$ \\
\hline
\end{tabular}

